\title{
A substituição das técnicas tradicionais de captura do caranguejo-uçá (Ucides cordatus) pela técnica "redinha" no estuário do rio Mamanguape, Paraíba
}

\author{
Douglas Macêdo do Nascimento ${ }^{1 *}$, José da Silva Mourão ${ }^{2}$ \& Rômulo Romeu Nóbrega Alves²
}

\begin{abstract}
${ }^{1}$ Departamento de Sistemática e Ecologia, Universidade Federal da Paraíba, Cidade Universitária, 58051-900, João Pessoa, Paraíba, Brasil.

${ }^{2}$ Departamento de Biologia, Universidade Estadual da Paraíba, Av. Baraúnas, 351 - Campo Universitário, Bodocongó, P.O. 58109-753, Campina Grande, Paraíba, Brasil.
\end{abstract}

\begin{abstract}
Resumo - O presente estudo foi desenvolvido em duas comunidades indígenas localizadas às margens do complexo estuário-manguezal do rio Mamanguape, Paraíba. O estudo identificou os motivos da rápida transição das técnicas tradicionais (braceamento e tapamento) para a "redinha". Nossos resultados mostraram que os caranguejeiros foram influenciados a mudar de técnica(s), principalmente pela maior produção obtida através da redinha. Além disto, fatores relacionados às desvantagens apresentadas pelas técnicas braceamento e tapamento, como a possibilidade maior de acidentes de trabalho e doenças adquiridas a partir da atividade de captura, reforçaram essa transição. Especificamente para o braceamento, um fator ligado a uma questão comportamental do caranguejo, de habitar galerias mais profundas, dificulta a captura através desta técnica. Essa rápida transição é preocupante do ponto de vista da conservação, porque a redinha é geradora de vários impactos ambientais, tidos como potenciais ameaças ao ecossistema manguezal e ao estoque populacional do caranguejo-uçá (Ucides cordatus). Deste modo, torna-se importante realizar estudos que busquem uma saída para um problema que é não somente ambiental, como também social, visto que as técnicas tradicionais são menos rentáveis que a redinha e que esta surgiu para facilitar o trabalho do catador e aumentar a sua renda.
\end{abstract}

Palavras-chave adicionais: comunidades tradicionais, etnoecologia, rompimento da tradicionalidade.

\begin{abstract}
The replacement of traditional capture techniques of caranguejo-uçá crabs (Ucides cordatus) by the redinha (little-net technique) in the Mamanguape River Estuary, Paraíba, Brazil) - Two traditional fishing communities situated on the margins of the Mamanguape River estuary-mangrove complex, Paraiba State, Brazil, were studied to determine the motivations for their rapid transition from traditional harvesting techniques (braceamento and tapamento) to redinha (little-net) trapping. Our results indicate that the crab harvesters were prompted into changing their techniques primarily due to higher production rates with redinha. Additionally, there were disadvantages in using both the braceamento and tapamento techniques (including greater chances of accidents and acquiring diseases) that reinforced this transition. The behavioral characteristic of the crabs living in denser gallery forest specifically hindered capture using the braceamento technique. This fast transition of harvesting techniques is a major concern from a conservation standpoint as the redinha causes environmental impacts and threatens both the mangrove ecosystem and the populations of caranguejo-uçá crabs (Ucides cordatus). Thus this study examined a problem that is both environmental and social, as traditional techniques were less profitable than the new harvesting method but had much less impact - while the redinha helps with crab harvesting and increases income at the cost of higher environmental impacts.
\end{abstract}

Aditional key words: ethnoecology, rupture of traditionality, traditional communities.

Os manguezais são ecossistemas costeiros situados em zonas tropicais e subtropicais que apresentam uma combinação complexa e intrínseca de aspectos bioecológicos. Aimportância biológica dos manguezais, sem dúvida, reside no fato de que esses ecossistemas abrigam muitas plantas, invertebrados (moluscos, crustáceos e outros) e vertebrados, que os usam como áreas de reprodução, alimentação e moradia durante todo ou parte do seu ciclo de vida (Hatcher et al. 1989; Robertson et al. 1992; Twilley et al. 1996). A fauna e a flora dos manguezais constituem uma complexa teia alimentar que é essencial para a saúde dos ecossistemas costeiros, bem como para o mar

\footnotetext{
*Autor para correspondência: douglasmacedo84@gmail.com

Editor responsável: Ulysses Paulino de Albuquerque

Recebido: 12 maio 2011; aceito: 20 set. 2011.
}

adjacente (Schaeffer-Novelli 1995), e estes ecossistemas são também utilizados por um grande número de pescadores de subsistência (Odum \& Heald 1972).

Muitas comunidades costeiras em todo o mundo dependem dos manguezais para a sua subsistência (Walters et al. 2008). Apesar de serem ambientes de elevada produtividade, que beneficiam direta e indiretamente uma vasta gama de organismos e pessoas que deles se utilizam, os manguezais têm sido alvo de inúmeras agressões decorrentes de ações antrópicas. Diante disso, estudos sobre esses ecossistemas e espécies a eles relacionadas são fundamentais, uma vez que podem fornecer subsídios para o estabelecimento de medidas que busquem a sua conservação.

A exploração inadequada dos recursos dos manguezais vem se configurando como uma das principais 
ameaças para esse ecossistema. No caso da fauna, um dos problemas é a adoção de técnicas de captura inovadoras, pois geralmente são eficientes e exigem menos esforço físico para explorar um determinado recurso natural (Botelho et al. 2000). Essas técnicas podem intensificar a captura, e isto combinado com a menor seletividade em relação às técnicas tradicionais pode exceder os limites de substituição de um determinado recurso, levando à sua diminuição e, consequentemente, ameaçando a sobrevivência das próprias comunidades tradicionais que dependem dele.

O Brasil tem $8.500 \mathrm{~km}$ de costa e a segunda maior área contínua de manguezais da Terra (Kjerfve et al. 1997). Os manguezais fornecem muitos recursos economicamente importantes, tais como madeira, produtos medicinais, corantes naturais, peixes, crustáceos e moluscos (Alves \& Nishida 2002, 2003; Alves et al. 2005; Mourão \& Nordi 2006; Nishida et al. 2006a; Rocha et al. 2008; Nordi et al. 2009). Os caranguejos Brachyura são recursos econômicos importantes para as populações humanas costeiras do Nordeste do Brasil. Estudos de gestão e sustentabilidade econômica em manguezais brasileiros sugerem que a captura tradicional de crustáceos é a atividade mais rentável para as populações humanas locais (Kjerfve \& Lacerda 1993; IBAMA 1995). Uma das principais atividades realizadas em ecossistemas de manguezal no Brasil é a captura de Ucides cordatus (Linnaeus, 1763). No estado da Paraíba, esta espécie é o crustáceo mais explorado por comunidades ribeirinhas que vivem nas proximidades de áreas de manguezais (Nordi 1992; Alves \& Nishida 2002, 2003; Alves et al. 2005; Nishida et al. 2006b).

A captura de caranguejos representa uma importante fonte de renda para populações ribeirinhas ao longo da costa paraibana (Alves \& Nishida 2003). Essa atividade é realizada por trabalhadores conhecidos como "catadores" ou caranguejeiros que, em sua maioria, são analfabetos de baixa renda e moram em residências precárias, carecendo de condições mínimas de higiene e conforto (Alves \& Nishida 2003; Nascimento 2007). Diferentes técnicas podem ser usadas para a captura do caranguejo, mas os catadores utilizam atualmente duas técnicas no estuário do rio Mamanguape, Paraíba: tapamento e redinha. Esta última é considerada predatória (Maneschy 1993; Botelho et al. 2000; Alves \& Nishida 2003; Nunes \& Samain 2004; Leite 2005) e consiste em uma armadilha confeccionada pelos caranguejeiros com fios de náilon desfiados a partir de sacos de polipropileno e amarrados nas pontas. Ela é armada na abertura da galeria do caranguejo-uçá com o auxílio de prolongamentos do caule principal do mangue-sapateiro ou mangue-vermelho (Rhizophora mangle L.), denominado pelos caranguejeiros de "raizes" ou "gaita" (Nascimento 2007).

Segundo catodores do estuário do rio Mamanguape, na Paraíba, a técnica redinha é causadora de vários impactos ambientais, tais como: mortalidade de caranguejos presos às redinhas abandonadas, corte das raízes de $R$. mangle, poluição do manguezal através dos fios de náilon, inutilidade das tocas dos caranguejos como hábitat devido à poluição, captura menos seletiva, elevada produtividade e maior produção que as obtidas por técnicas tradicionais (Nascimento 2007). Adicionalmente, o uso da redinha também ocasiona impactos de cunho social referentes a conflitos decorrentes da não aceitação da utilização da armadilha (principalmente pelos caranguejeiros tradicionais), rompimento de tradições (perda da cultura tradicional) e substituição e desuso das técnicas tradicionais pela maior aceitação da redinha.

A técnica redinha foi criada no Rio de Janeiro, Brasil, provavelmente, no início da década de 1980 (Nunes \& Samain 2004), e começou a ser difundida na Paraíba ainda nos anos 80 (Nascimento 2007). No estuário do rio Mamanguape, área onde foi realizada a presente pesquisa, a redinha é a técnica que atualmente tem uso majoritário, apesar da proibição de sua utilização no Norte e Nordeste do país pelo Instituto Brasileiro do meio ambiente e dos Recursos Naturais Renováveis (IBAMA) através da Portaria IBAMA N ${ }^{\circ}$ 034/ 03-N de junho de 2003.

Alves \& Nishida (2003) afirmam que o uso da redinha indica uma clara ruptura dos padrões tradicionais de captura, pois exige menos esforço físico por parte do catador do que o exigido pela técnica do tapamento. A introdução desta nova tecnologia tem implicações claras para a conservação, pois embora esta prática seja considerada predatória e esteja legalmente proibida, é amplamente utilizada em várias áreas de manguezais do Brasil. Diante desse contexto, esse trabalho buscou identificar os motivos da rápida transição das técnicas tradicionais para a redinha no estuário do rio Mamanguape - PB, no intuito de fornecer informações relevantes aos órgãos ambientais de pesca.

\section{Material e Métodos}

Área de estudo. $\mathrm{O}$ estuário do rio Mamanguape abrange 16.400 ha ( $06^{\circ} 43^{\prime} 02^{\prime \prime}-06^{\circ} 51^{\prime} 54^{\prime \prime}$ 'S e $35^{\circ} 07^{\prime} 46^{\prime \prime}$ 3454'04"W; Figura 1) e está situado nos limites da Área de Proteção Ambiental (APA) da Barra do Rio Mamanguape, Paraíba, Brasil. O estuário é composto por uma área de manguezal (5.400 ha), camboas (ramos do rio principal que cortam o mangue), croas (bancos areno-lodosos presentes no rio), apicuns (áreas sem vegetação típica de mangue) e uma barreira de recife perpendicular à sua desembocadura.

As comunidades de Tramataia e Três Rios (município de Marcação, Paraíba), localidades do estudo da presente pesquisa, são aldeias indígenas habitadas por uma mistura de índios de etnia Potiguara, negros e descendentes de europeus que praticam atividades extrativistas no estuário do rio Mamanguape (Mourão \& Nordi 2003). Vários animais são extraídos do complexo estuário-manguezal, como moluscos [Anomalocardia brasiliana (Gmelin, 1791), Crassostrea brasiliana (Lamarck, 1819) e Mytella spp.], 




Figura 1. Estuário do rio Mamanguape: A- Vista aérea (foto: Dirceu Tortorello, 2008); B- Mapa georreferenciado (adaptado do Mapa da SUDEMA: http://www.aesa.pb.gov.br/geoprocessamento/ geoportal/index.php; Xavier et al., no prelo).

crustáceos [Cardisoma guanhumi (Latreille, 1825), Goniopsis cruentata (Latreille, 1803), Callinectes spp., Penaeus subtilis (Farfante, 1967), P. schmitti (Burkenroad, 1938), Ucides cordatus (Linnaeus, 1763)], além de várias espécies de peixes. No entanto, a atividade econômica mais importante realizada pelas comunidades que vivem próximo ao estuário é a captura de $U$. cordatus (Paludo \& Klonowski 1999). Essas comunidades têm uma forte relação com o manguezal, uma vez que ele representa a única fonte de subsistência. Apesar de habitarem uma região muito rica em recursos naturais, as populações sofrem de deficiências em termos de assistência médica, educação e saneamento básico (Mourão 2000).

Procedimentos. O trabalho de campo foi realizado mensalmente, entre março e dezembro de 2010, dividido em duas etapas. Na primeira etapa da pesquisa (março e abril), foram realizados levantamentos para selecionar os informantes. As visitas iniciais foram realizadas com a finalidade de estabelecer a confiança mútua entre o pesquisador e o entrevistado e definir o perfil da população alvo. A segunda etapa foi desenvolvida entre maio e dezembro, utilizando as seguintes técnicas para obtenção de dados: entrevistas abertas e semiestruturadas (Mello 1986). As primeiras entrevistas foram abertas ou livres e a partir delas os entrevistados espontaneamente discutiram o tema proposto, servindo de base à formulação das entrevistas semiestruturadas.
As entrevistas semiestruturadas foram realizadas com 66 catadores de caranguejo-uçá das comunidades visitadas. As perguntas abordaram aspectos gerais do processo de captura e questões específicas, tais como o uso da redinha. Os entrevistados foram selecionados a partir da técnica Snowball (Bola de Neve) (Biernacki \& Waldorf 1981), que consiste em seguir as indicações dos primeiros entrevistados para localizar os demais alvos da pesquisa. Os primeiros entrevistados foram indicados por um guia local da comunidade Tramataia. Nas comunidades estudadas, a atividade é realizada exclusivamente por homens. As entrevistas, posteriormente transcritas, foram gravadas em um dispositivo MP3, sempre precedidas pela identificação do entrevistador com uma explicação sucinta sobre o propósito do estudo e um pedido de permissão para gravá-las.

A validade das informações foi obtida por meio das técnicas de controle de dados com entrevistas em situações sincrônicas (as mesmas perguntas foram aplicadas para pessoas diferentes ao mesmo intervalo de tempo) e diacrônicas (a mesma pergunta foi feita à mesma pessoa em um intervalo de tempo distante) (Marques 1991), neste caso, de três meses.

\section{Resultados E Discussão}

Técnicas de captura do caranguejo-uçá no estuário do rio Mamanguape. Na captura definida como braceamento, a coleta é feita de forma manual, com os catadores introduzindo o braço nas galerias, onde os animais se abrigam, para retirá-los após imobilizados.

$\mathrm{O}$ tapamento consiste na obstrução de certo número de tocas com sedimentos do mangue que são empurrados para o seu interior com o auxílio dos pés (Figura 2). Após ter sido tapado um determinado número de tocas, os catadores retornam às tocas tapadas para coleta dos caranguejos. Segundo os catadores, os caranguejos tapados encaminham-se para a parte superior da galeria à procura de ar, sendo capturados sem oferecer resistência.

A ratoeira consiste em armadilhas construídas com latas de óleo ou similares, das quais se retira uma das tampas que, reforçada com pedaços de madeira, é novamente fixada à lata por meio de um pedaço de borracha, que funciona como dobradiça. Devidamente iscadas, as armadilhas são colocadas nas bordas das tocas dos caranguejos.

A redinha consiste em uma armadilha formada por fios de sacos plásticos amarrados, que é colocada nas aberturas das tocas, fixada com o auxílio de duas metades de "raiz" de R. mangle; ao tentarem sair, os caranguejos ficam presos, sendo então capturados (Figura 3).

Como foi exposto, a forma de captura do caranguejouçá é manual, secundada por instrumentos rústicos adaptados pelo próprio catador e exercida nos horários de maré baixa (Nordi 1992). Esse e outros autores registraram o 

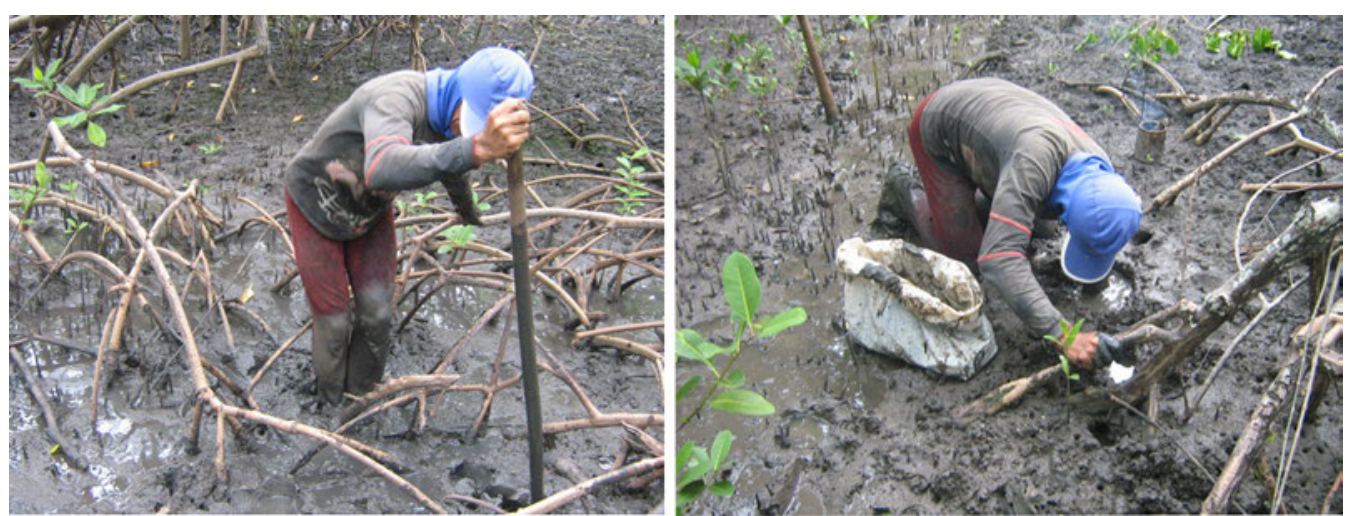

Figura 2. Caranguejeiro obstruindo a toca do caranguejo-uçá (à esquerda) e o caranguejo sendo retirado manualmente da toca (à direita) no manguezal do estuário do rio Mamanguape, Paraíba (fotos: José Mourão, 2007).

uso dessas quatro formas de captura em manguezais do estado da Paraíba (Alves \& Nishida 2003; Nordi et al. 2009).

Motivos da transição de técnicas tradicionais (braceamento e tapamento) para a redinha. A prática da redinha substituiu a técnica do braceamento, e o tapamento passa por esse processo. Dos entrevistados $(n=66)$ das comunidades pesquisadas no presente estudo (Tramataia e Três Rios), $91 \%$ afirmaram utilizar a redinha e apenas 9\% o tapamento (técnica tradicional remanescente). Dados registrados em 2002, baseados em entrevistas com 70 catadores de caranguejo-uçá do estuário do rio Mamanguape (Alves \& Nishida 2003), revelam uma distribuição de catadores por técnica de captura diferente: $44 \%$ utilizavam o tapamento, $43 \%$ o tapamento e o braceamento, $10 \%$ a redinha e apenas $3 \%$ o braceamento. Vários fatores contribuíram para a transição das técnicas tradicionais (braceamento e tapamento) utilizadas no estuário do rio Mamanguape para a redinha. Muitos deles estão relacionados às desvantagens apresentadas pelo tapamento e braceamento, tais como: possibilidade maior de acidentes de trabalho, doenças adquiridas durante a prática cotidiana na captura através dessas técnicas e menor produção quando comparada à obtida com o uso da redinha.

Os caranguejeiros entrevistados afirmaram que os acidentes de trabalho e doenças adquiridas (a partir da prática da atividade de captura) são mais frequentes entre os que usam técnicas tradicionais. No exercício do braceamento e tapamento, são sofridos arranhões, cortes e rasgos na pele, principalmente durante a introdução do braço na toca do caranguejo (Figura 4), devido ao maior contato com pontas afiadas de raízes e troncos e conchas de ostras cortantes [Crassostrea rhizophorae (Guilding, 1828 )] aderidas às raízes de $R$. mangle. Durante a captura, essas escoriações também podem ocorrer quando o tapador, ao se levantar na hora da despesca (situação em que fica de cócoras ou deitado no substrato para retirar o caranguejo da toca), eventualmente bate alguma parte do seu corpo nas pontas de raízes escoras cortadas pelo catador que utiliza redinha. Isto é evidenciado no trecho do depoimento de um dos catadores: "Pode quando se levantar assim pra tirar um caranguejo, que vai se levantar pode meter a cabeça, as costas naquelas pontas da gaita que ele tem cortado (o caranguejeiro que utiliza redinha)" (caranguejeiro de Três Rios). Os caranguejeiros ainda relatam cortes em decorrência das eventuais "mordidas" (pinçadas) dos caranguejos no momento de sua retirada da toca.

As doenças adquiridas no trabalho citadas pelos caranguejeiros foram: dores nas costas (devido ao
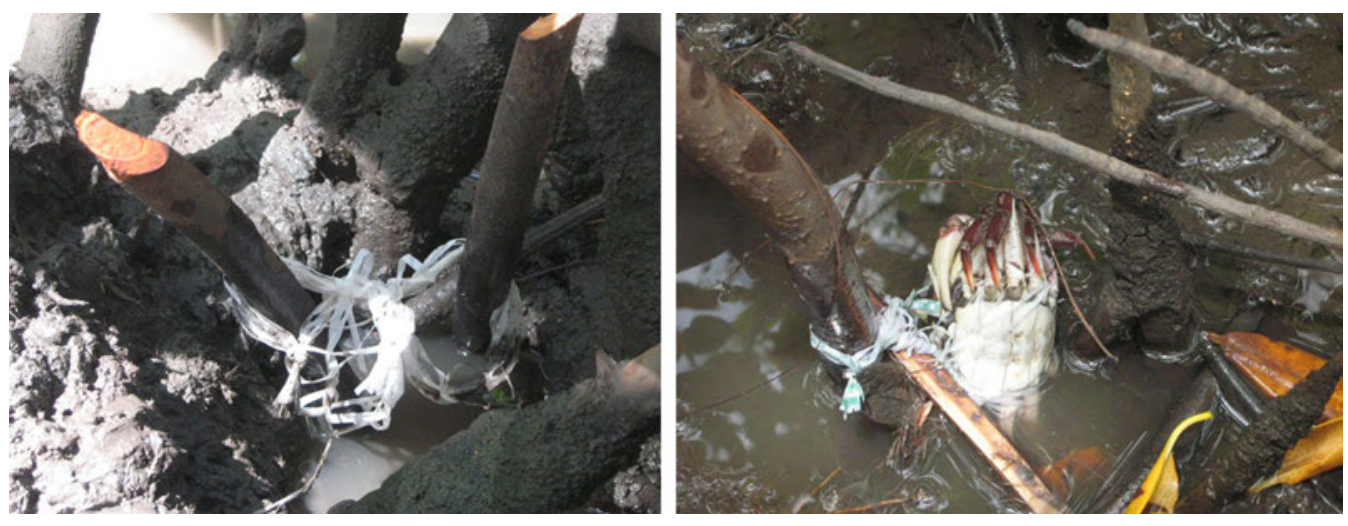

Figura 3. Redinha armada na abertura de uma toca de caranguejo-uçá (à esquerda) e animal aprisionado a uma redinha (à direita) no estuário do rio Mamanguape, Paraíba (fotos: José Mourão, 2007). 


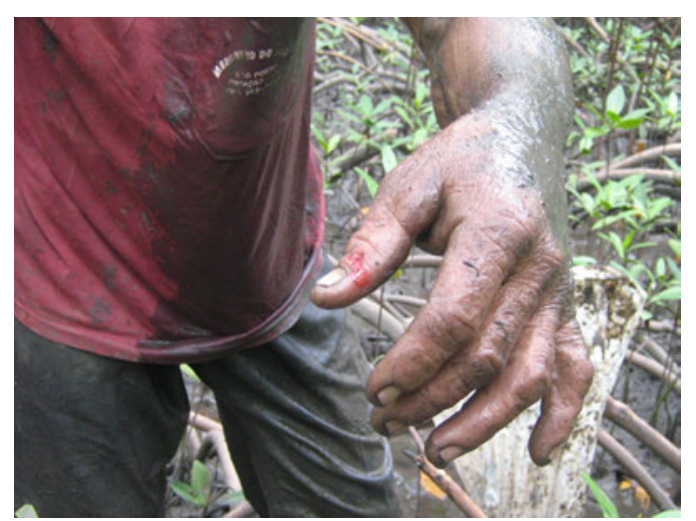

Figura 4. Caranguejeiro do tapamento, mostrando o corte no polegar advindo de estrepe do mangue (foto: José Mourão, 2007).

movimento de agachar inúmeras vezes), micoses (manchas brancas na pele) e verminoses, que para alguns, são adquiridas através do contato com dejetos do guaxinim [(Procyon cancrivorus (Cuvier, 1798)], predador natural dos caranguejos, ou pelo contato com caranguejos.

Os caranguejeiros que utilizam o tapamento (técnica tradicional remanescente) são fisicamente reconhecidos por algumas marcas no corpo provenientes de seu trabalho, tais como braços arranhados e cortados, unhas das mãos encardidas, manchas brancas no corpo (provavelmente micoses), especialmente nas mãos, e pela presença de poucos pelos em um dos braços e nos joelhos, em virtude do atrito da pele com o sedimento nos momentos de tapagem e retirada (despesca) do caranguejo. O relato de um excaranguejeiro evidencia essa situação: "O pescador de caranguejo que é profissional já de muito tempo que ele enfia o braço tudo eles tem um sinal no braço. Um sinal na mão. Isso aqui ainda é sinal. Tá vendo essas pintas? $O$ cabelo... não tem cabelo no braço. Nem tem cabelo no joelho. Isso aqui não tem cabelo. Porque ele vai se ajoelhar na lama pra enfiar o braço né? E ali vem cacareco de ostra, vem os estrepo do mangue, ali vai furando, vai cortando. O couro disso aqui dele é grosso. É grosso e sem cabelo." (ex-caranguejeiro de Marcação).

De acordo com todos os caranguejeiros, as técnicas tradicionais apresentam menor produção que a redinha. Eles ainda afirmam que, aliado a isso, a redinha é de fácil aprendizado, rápido manuseio e boa eficiência. Essas são as principais razões que explicam a adoção da redinha em detrimento das técnicas tradicionais. Segundo os catadores, a eficiência da redinha é significativamente alta, isto porque muitas armadilhas obtêm sucesso na captura e mesmo aquelas que não capturaram no dia em que são armadas, podem obter êxito no dia seguinte, o que não ocorre para o tapamento.

Os catadores entrevistados afirmam que o braceamento entrou em desuso principalmente porque os caranguejos atualmente habitam galerias mais profundas, deste modo o braço não pode alcançá-los, tornando a captura inviável. Os caranguejeiros relatam que este comportamento dos caranguejos (habitar tocas mais profundas) foi observado após a mortalidade em massa de caranguejo-uçá, ocorrida há alguns anos. O depoimento a seguir ilustra essa situação: "Hoje, você não consegue arrancar o caranguejo a braço, é muito difícil, é raro demais. Caranguejo, hoje, depois dessa mortalidade, ele ficou fundo de um jeito e só procura os canto mais difícil, mais difícil" (caranguejeiro de Tramataia). Sendo assim, a técnica da redinha tornou-se a primeira opção para a captura do caranguejo. Alves \& Nishida (2002) relataram que essa mortalidade citada pelos catadores ocorreu em 1998 nos manguezais da Paraíba, gerando uma redução do estoque natural do caranguejo-uçá, criando problemas sociais e afetando seriamente a situação econômica da população que dependia desse recurso.

No ano em que ocorreu a mortalidade no estuário do rio Mamanguape, a captura ficou impossibilitada e os catadores tiveram que recorrer a manguezais de outros estados, principalmente os do Rio Grande do Norte (manguezais do estuário do rio Piranhas-Açu e estuário do rio Curimataú). De acordo com os catadores, nessas localidades a forma de captura predominante na época era a redinha. Diante das vantagens da redinha e das muitas desvantagens do tapamento (principalmente a menor produção), muitos tapadores passaram a utilizá-la e permanecem utilizando essa técnica. Existem poucos catadores remanescentes que usam o tapamento, sendo encontrados somente dois na comunidade de Tramataia e quatro em Três Rios. Estes, quando perguntados por que não aderiram à redinha, disseram que não concordam com a prática por seus muitos impactos ambientais, porque não sabem utilizá-la e nem têm a habilidade necessária para o exercício dessa forma de captura.

Segundo os catadores entrevistados no presente trabalho, com a utilização das técnicas tradicionais, a produção fica abaixo daquela alcançada anteriormente à mortalidade. A utilização da redinha minimiza esse problema por propiciar uma maior produção, resultado da sua boa eficiência juntamente com a possibilidade de forragear um número maior de tocas. Os catadores jovens que utilizam redinhas não são proficientes nas técnicas tradicionais e aderem facilmente às novas técnicas em busca de maior produção com menos esforço físico, o que contribui para a erosão cultural das técnicas tradicionais de captura (e todos os seus conhecimentos associados).

Nunes \& Samain (2004) também observaram a substituição de técnicas tradicionais pela redinha em manguezais de Vitória, estado do Espírito Santo. Segundo estes autores, além dos caranguejeiros, muitos desempregados adotaram a pesca do caranguejo através da redinha como alternativa de subsistência pela facilidade da sua utilização. Esses dados revelam que as técnicas tradicionais de captura de caranguejo-uçá no Brasil vêm caindo em desuso, corroborando as constatações de outros autores (Passos \& Di Beneditto 2005; Jankowsky et al. 2006; 
Castilho et al. 2008), que vem demonstrando que a técnica redinha foi substituindo as técnicas tradicionais de captura, apesar das proibições legais impostas pelos órgãos ambientais. Devido à boa produtividade e à facilidade de uso, mencionada pelos próprios catadores, a técnica redinha tem se espalhado rapidamente pela maioria das comunidades de caranguejeiros e, portanto, a pressão de captura pode estar se intensificando. O tapamento, técnica tradicional remanescente na área de estudo, encontra-se em processo de substituição pela redinha e seriamente ameaçada de desaparecer das comunidades, visto que os novos caranguejeiros estão aderindo à redinha. Esse fato é preocupante, uma vez que tal mudança pode ter importantes implicações para a conservação da espécie. Conforme apontam Alves \& Nishida (2003), a observação da diminuição dos estoques de caranguejo-uçá pelos caranguejeiros do estuário do rio Mamanguape e a introdução de técnicas de captura predatórias nos manguezais paraibanos alerta para o problema de uma possível ameaça à manutenção da espécie em níveis ecologicamente sustentáveis. Ainda segundo esses autores, muitas pessoas veem os manguezais como uma alternativa de trabalho, aumentando a pressão sobre aqueles recursos mais importantes economicamente, como o caranguejo-uçá. Dessa forma, é crescente o aumento do número de pessoas que acorrem aos manguezais em busca de uma fonte de subsistência, sendo a captura do caranguejo-uçá uma das atividades mais praticadas por estes. Esses novos "catadores" não dominam as técnicas de captura praticadas pelos catadores tradicionais. Em busca de maior eficiência de exploração a um menor esforço físico, introduzem novas técnicas de captura, consideradas predatórias, como é o caso da redinha, que, como foi evidenciado no presente estudo, vem substituindo as técnicas tradicionais e todo o conhecimento associado a elas. Alves \& Nishida (2002) apontam que os catadores tradicionais possuem profundo conhecimento sobre o ciclo biológico da espécie $U$. cordatus e mostram uma preocupação constante com a preservação da espécie, uma vez que dependem diretamente desse recurso para sua sobrevivência.

A substituição das técnicas tradicionais pela redinha é influenciada também pelo mercado consumidor, que exige uma produção cada vez maior, corroborando uma tendência destacada por Alves \& Nishida (2003), de que as populações de catadores sofrem a influência de transformações históricas, estando integradas a economia de mercado e aos sistemas políticos, o que acaba por interferir no modo de vida, nas formas de exploração do recurso e na riqueza cultural dessas comunidades. Nordi (1992) ressalta que a situação de extrema carência por que passam essas comunidades, associada aos vários fatores que influenciam a pesca artesanal, como a imprevisibilidade de captura e a incerteza do mercado, podem levar a situações em que as populações não sejam capazes de atuar em harmonia com a natureza.

\section{Considerações Finais}

O uso majoritário da técnica redinha no estuário do rio Mamanguape, em decorrência da rápida substituição das técnicas anteriormente utilizadas, é uma ameaça à extinção definitiva das técnicas tradicionais (menos impactantes e mais importantes culturalmente). Esta substituição gera uma grande preocupação para os órgãos ambientais e as comunidades quanto à conservação do caranguejo-uçá, porque a redinha é causadora de vários impactos ambientais diretos à conservação do estoque populacional desse recurso, e também impactos indiretos que contribuem para degradação do ecossistema manguezal.

Diante da falta de dados quantitativos sobre os impactos ambientais e da grande importância sócioeconômica da comercialização do caranguejo-uçá se faz necessário aprofundar os estudos que envolvem todos os aspectos relacionados à captura através da redinha, numa tentativa de minimizar os problemas socioambientais decorrentes. Compreender como e por que os caranguejeiros capturam o caranguejo-uçá e como os padrões de uso afetam o manguezal, a espécie e eles próprios, são pontos fundamentais para uma gestão efetiva e participativa, propondo soluções adequadas à realidade da captura de cada região.

\section{REFERÊNCIAS}

Alves, R.R.N \& Nishida, A.K. 2002. A ecdise do caranguejo-uçá, Ucides cordatus (Crustacea, Decapoda, Brachyura) na visão dos caranguejeiros. Interciencia 27: 110-117.

Alves, R.R.N \& Nishida, A.K. 2003. Aspectos socioeconômicos e percepção ambiental dos catadores de caranguejo-uçá Ucides cordatus cordatus (L. 1763) (Decapoda, Brachyura) do estuário do rio Mamanguape, Nordeste do Brasil. Interciencia 28: $36-43$.

Alves, R.R.N.; Nishida, A.K \& Hernandez, M.I.M. 2005. Environmental perception of gatherers of the crab caranguejouçá (Ucides cordatus, Decapoda, Brachyura) affecting their collection attitudes. Journal of Ethnobiology and
Ethnomedicine 1: 1-8.

Biernarcki, P.E. \& Waldorf, D. 1981. Snowball sampling problems and techniques of chain referral sampling. Sociological Methods and Research 10: 141-163.

Botelho, E.R.O; Santos, M.C. \& Pontes, A.C.P. 2000. Algumas considerações sobre o uso da redinha na captura do caranguejouçá, Ucides cordatus (Linnaeus, 1763), no litoral sul de Pernambuco-Brasil. Boletim Técnico- Científico do CEPENE 8: 55-71.

Castilho, G.G.; Ostrensky, A; PIE, M. \& Boeger, W. 2008. Estado da arte das pesquisas com o caranguejo-uçá, Ucides cordatus. Archives of Veterinary Science 13: 151-166. 
Hatcher, B.G.; Johannes, R.E. \& Robertson, A.I. 1989. Review of research relevant to conservation of shallow tropical marine ecosystems. Oceanography and Marine Biology: Annual Review 27: 337-414.

IBAMA (Instituto Brasileiro do Meio Ambiente e dos Recursos Naturais Renováveis). 1995. Os Ecossistemas Brasileiros e os Principais Macrovetores de Desenvolvimento: subsídios ao planejamento da gestão ambiental. Ministério do Meio Ambiente, Brasília.

Jankowsky, M.; Pires, J.S.R. \& Nordi, N. 2006. Contribuições para o manejo participativo do caranguejo-uçá, Ucides cordatus, no Município de Cananéia - SP. Boletim do Instituto de Pesca 32: 221-228.

Kjerfve, B. \& Lacerda, L.D. 1993. Management and status of the mangroves of Brazil. In: L.D. Lacerda (coord.), Conservation and Sustainable Utilization of Mangrove Forests in Latin America and Africa Regions. ISME/ ITTO, Okinawa, p. 245-272.

Kjerfve, B.; Lacerda, L.D. \& Diop, E.S. (eds) 1997. Mangrove Ecosystem Studies in Latin America and Africa. UNESCO/ ISME/USDA, Paris.

Leite, M.M.L. 2005. Relações Morfométricas para a Compreensão de Aspectos Reprodutivos do Caranguejo-uçá Ucides cordatus (LINNAEUS, 1763), no Estuário do Rio Coreaú - Ceará. Dissertação (Mestrado em Ciências Marinhas Tropicais). Universidade Federal do Ceará.

Maneschy, M.C. 1993. Pescadores nos manguezais: estratégias técnicas e relações sociais de produção na captura de caranguejo. In: L.G. Furtado, W. Leitão \& A.F. Melo. (eds), Povos das Águas: realidade e perspectivas na Amazônia. Museu Paraense Emílio Goeldi, Belém, p. 19-62.

Marques, J.G.W. 1991. Aspectos Ecológicos na Etnoictiologia dos Pescadores do Complexo Estuarino-Lagunar MundaúManguaba. Tese (Doutorado em Ecologia). Universidade Estadual de Campinas.

Mello, L.C. 1986. Antropologia Cultural: iniciação, teoria e temas. Editora Vozes, Petrópolis.

Mourão, J.S. 2000. Classificação e Ecologia dos Peixes Estuarinos por Pescadores do Estuário do Rio Mamanguape - PB. Tese (Doutorado em Ecologia e Recursos Naturais). Universidade Federal de São Carlos.

Mourão, J.S. \& Nordi, N. 2003. Etnoictiologia de pescadores artesanais do estuário do rio Mamanguape, Paraíba, Brasil. Boletim Técnico do Instituto de Pesca 29: 9-17.

Mourão, J.S. \& Nordi, N. 2006. Pescadores, peixes, espaço e tempo: uma abordagem etnoecológica. Interciencia 31: 1-7.

Nascimento, D.M. 2007. Impactos Sócio-ambientais Provocados pela Técnica "Redinha" na Captura do Caranguejo-uçá (Ucides cordatus) no Estuário do Rio Mamanguape - PB. Monografia (Graduação em Ciências Biológicas). Universidade Estadual da Paraíba.

Nishida, A.K.; Nordi, N. \& Alves, R.R.N. 2006a. Mollusk gathers of Northeast Brazil: gathering techniques and productivity. Human Ecology 34: 133-145.

Nishida, A.K.; Nordi, N. \& Alves, R.R.N. 2006b. Molluscs production associated to lunar-tide cycle: a case study in Paraíba state. Journal of Ethnobiology and Ethnomedicine 2: $1-6$.

Nordi, N. 1992. Os Catadores de Caranguejo-uçá (Ucides cordatus) da Região de Várzea Nova (PB): uma abordagem ecológica e social. Tese de Doutorado (Ecologia e Recursos Naturais). Universidade Federal de São Carlos.

Nordi, N.; Nishida, A.K. \& Alves, R.R.N. 2009. Effectiveness of two gathering techniques for Ucides cordatus in Northeast Brazil: implications for the sustainability of mangrove ecosystems. Human Ecology 37: 121-127.

Nunes, A.A. \& Samain, E. 2004. Os Argonautas do Mangue Precedido de Balinese Character (Re)visitado.: Editora Unicamp e Imprensa Oficial do Estado de São Paulo, Campinas e São Paulo.

Odum, W.E. \& Heald, E.J. 1972. Trophic analyses of an estuarine mangrove community. Bulletin of Marine Science 22: 671738.

Paludo, D. \& Klonowski, V.S. 1999. Barra de Mamanguape PB: estudo do impacto do uso de madeira de manguezal pela população extrativista e da possibilidade de reflorestamento e manejo dos recursos madeireiros. MAB - UNESCO MMA, n. 16, Série Cadernos da Reserva da Biosfera da Mata Atlântica, São Paulo.

Passos, C.A. \& Di Beneditto, A.P.M. 2005. Captura comercial do caranguejo-uçá, Ucides cordatus (L., 1763), no manguezal de Gargaú, RJ. Biotemas 18: 223-231.

Robertson, A.I.; Alongi, D.M. \& Boto, K.G. 1992. Food chains and carbon fluxes. In: A.I. Robertson \& D.M. Alongi (eds), Tropical Mangrove Ecosystems. American Geophysical Union Press, Washington, p. 293-326.

Rocha, M.S.P.; Mourão, J.S.; Souto, M.S.W.; Barboza, R.R.D \& Alves, R.R.N. 2008. O uso dos recursos pesqueiros no estuário do rio Mamanguape, estado da Paraíba, Brasil. Interciencia 33: 903-909.

Schaeffer-Novelli, Y. 1995. Manguezal: ecossistema entre a terra e o mar. Caribbean Ecological Research, São Paulo.

Twilley, R.R.; Snedaker, R.R.; Yáñez-Arancibia, S.C. \& Medina, A. 1996. Biodiversity and ecosystem processes in tropical estuaries: perspectives of mangrove ecosystems. In: H.A. Mooney, J.H. Cushman, E. Medina, O.E. Sala \& E.D. Schulze (eds), Functional Roles of Biodiversity: a global perspective. John Wiley and Sons, New York, p. 327-370.

Walters, B.B.; Rönnbäck, P.; Kovacs, J.; Crona, B.; Hussain, S.; Badola, R.; Primavera, J.; Barbier, E.B. \& Dahdoughguebas, F. 2008. Ethnobiology, socio-economics and adaptive management of mangroves: a review. Aquatic Botany 89: 220236.

Xavier, J.H.A.; Cordeiro, C.A.M.M.; Tenório, G.D.; Diniz, A.F.; Júnior, E.P.N.P.; Rosa, R.S. \& Rosa, I.L. (no prelo). Fish assemblage of the Mamanguape Environmental Protection Area, NE Brazil: abundance, composition and microhabitat availability along the mangrove-reef gradient. Neotropical Ichthyology. 